\title{
World Journal of Size of atrial septal defect after balloon
Pediatric Surgery atrial septostomy does not correlate with immediate improvement in oxygenation
}

Kartik Sehgal (D , ${ }^{1}$ Kunal Sehgal, ${ }^{2}$ Suraj Varma ${ }^{3}$

To cite: Sehgal K, Sehgal K, Varma S. Size of atrial septal defect after balloon atrial septostomy does not correlate with immediate improvement in oxygenation. World $\mathrm{Jnl}$ Ped Surgery 2021;4:e000224. doi:10.1136/wjps-2020-000224

KS and KS contributed equally.

Received 20 0ctober 2020 Revised 8 February 2021 Accepted 9 February 2021

Check for updates

\section{(C) Author(s) (or their} employer(s)) 2021. Re-use permitted under CC BY-NC. No commercial re-use. See rights and permissions. Published by BMJ.

${ }^{1}$ Monash University, Melbourne, Victoria, Australia

${ }^{2}$ Monash University, Clayton, Victoria, Australia ${ }^{3}$ Monash Heart, Monash Health, Clayton, Victoria, Australia

Correspondence to Dr Kartik Sehgal; kseh0002@ student.monash.edu

\section{ABSTRACT}

Objective Transposition of great arteries is a common cyanotic heart defect. Balloon atrial septostomy aims to improve circulatory mixing and oxygenation. Previous studies have combined infants with intact ventricular septum and those with ventricular septal defect.

Additionally, the septostomy was performed much later after birth. The objectives were to ascertain any correlation between the atrial septal defect size and oxygenation, before and after septostomy, as well the change in parameters pre-post procedure.

Methods We performed an audit of the last 10 years of clinical and echocardiographic data (2010-2020) for infants with transposition of great arteries with intact ventricular septum. A pediatric cardiologist, masked to clinical data, reviewed the images.

Results Our study of 25 infants with transposition of great arteries with intact ventricular septum noted that the procedure was performed at a median [interquartile range (IQR)] of $3(2,4)$ hours after birth. Prostaglandin was administered to the majority of infants [20/25 (80\%)]. While significant increases in partial pressure of oxygen $(24 \pm 5$ vs $40 \pm 6 \mathrm{mmHg}, \mathrm{p}<0.001)$ and preductal oxygen saturations $(67 \% \pm 18 \%$ vs $81 \% \pm 11 \%, p=0.003)$ were noted, and while the atrial septal defect increased in size from $1.8 \pm 0.6$ vs $4.8 \pm 0.7 \mathrm{~mm}(p<0.001)$, no correlation was noted between atrial septal defect size and oxygen saturations.

Conclusions In our study of infants with transposition of great arteries and intact ventricular septum managed with balloon atrial septostomy, no correlation was noted between the atrial septal defect size and oxygen saturations. Pulmonary vascular resistance and pulmonary blood flow may be important physiological variables determining oxygenation.

\section{INTRODUCTION}

Transposition of great arteries (TGA) is a common cyanotic heart disease in childhood. The incidence is approximately 3 per 10000 live births per year. Anatomically, the circulation is characterized by a mismatch in the ventriculo-arterial connections. Physiologically, this results in a parallel circulation, which is clinically characterized by hypoxia [low saturations and partial pressure

\section{Key messages}

What is already known about this subject?

- Transposition of great arteries is a common cyanotic heart disease.

- Balloon atrial septostomy is performed to improve circulatory mixing.

- Studies have combined infants with and without ventricular septal defects.

\section{What are the new findings?}

- This study exclusively studied infants with transposition and intact ventricular septum.

- Septostomy was performed very early on the first postnatal day.

- While oxygenation improved significantly, no correlations were noted with the size of atrial septal defects.

How might it impact on clinical practice in the foreseeable future?

- Clinicians will appreciate that other variables, such as pulmonary hemodynamics, influence oxygenation beyond the size of the atrial septal defect.

- Infants could be referred for early arterial switch instead of continued attempts to enlarge the septal defect.

of oxygen $\left.\left(\mathrm{paO}_{2}\right)\right]$ and cyanosis. Inadequate mixing may progress to acidosis, elevated lactate, poor urine output and eventual circulatory collapse (systemic constructs of hypoxia and anaerobic metabolism). Infants with TGA and intact ventricular septum (IVS) are at a higher risk of this clinical course. Mixing between the two parallel arms of circulations is required, either at ductal or atrial/ventricular levels. Balloon atrial septostomy (BAS) and intravenous prostaglandin (PGE1) allow palliation before a subsequent arterial switch. However, it is unclear whether the atrial septal defect (ASD) size correlates with oxygenation. An earlier study indicated ASD size to be the primary factor influencing oxygenation before BAS. ${ }^{1}$ Recent studies in 
infants with TGA with and without a ventricular septal defect (VSD) have noted no correlation between ASD size and oxygen saturation levels. ${ }^{2}$ The pre-existing literature also combines infants with IVS and VSD, making data potentially heterogeneous.

The objectives of this study were to ascertain change in oxygenation status in infants with D-TGA and IVS undergoing BAS and to determine correlation between ASD size and oxygenation.

\section{METHODS}

A retrospective audit of data over 10 years (2010-2020) was performed for infants with D-TGA with IVS who had undergone BAS. Clinical and echocardiographic data were retrieved from the archived database. Oxygenation data for equal time duration either side of the procedure were compared. The study was performed at a tertiary perinatal center with onsite pediatric cardiology and fetal diagnostic service. Management plans were made jointly between pediatric cardiology and the neonatal teams. The infants were sedated with morphine and/or midazolam, and muscle relaxation was achieved using pancuronium/ atracurium before intubation and mechanical ventilation. A preprocedure echocardiogram was performed to assess anatomy, ductal patency, interatrial communication size and overall cardiac function. As per the Unit guideline, PGE1 infusion was started based on preductal saturations $(<75 \%)$ and/or restrictive interatrial shunting. Infants were transferred to another tertiary center in the same city for the arterial switch procedure. A single cardiologist masked to the clinical data measured the ASD diameter between torn edges in two-dimensional mode. Data are presented as mean \pm standard deviation $(\mathrm{SD})$ or median [interquartile range (IQR)]. Student's t-test was used for the comparison of pre-post procedure variables. Pearson coefficient was used to determine correlation between ASD size and oxygenation.

\section{RESULTS}

Twenty-five infants fulfilled the inclusion criteria. Table 1 shows demographic and clinical variables. Antenatal diagnosis was made in 23/25 (92\%) infants. PGE1 infusion was administered in a majority of infants. Infants blood gas parameters preprocedure included $\mathrm{pH} 7.25 \pm 0.6$ and base deficit 2.8 \pm 1 . All the infants needed respiratory support (nasal continuous positive airway pressure) at the time of birth in the lead up to the procedure. Table 2 shows significantly improved oxygen after BAS. The overall increase in $\mathrm{paO}_{2}$ was $15 \pm 5 \mathrm{mmHg}$. Eleven $(44 \%)$ infants achieved $<10 \%$ increase in saturations after BAS; the overall increase was median (IQR) $10 \%$ $(7,26)$. The size of ASD increased significantly $(1.8 \pm 0.6$ vs $4.8 \pm 0.7 \mathrm{~mm}, \mathrm{p}<0.001)$. The post-BAS ASD size between those recording less than or more than $10 \%$ increase in saturations was comparable $(4.7 \pm 0.6$ vs $4.94 \pm 0.7 \mathrm{~mm}$, $\mathrm{p}=0.4)$. No significant correlation was noted between pre-BAS or post-BAS ASD size and any of the pre-BAS or

\begin{tabular}{ll}
\hline $\begin{array}{l}\text { Table } 1 \\
(\mathrm{n}=25)\end{array}$ & Demographic and clinical variables of the cohort \\
\hline Variable, $\mathbf{n}(\%)$ & Value \\
\hline Gestational age $(\mathrm{wk})^{\star}$ & $38 \pm 2.3$ \\
\hline Birth weight $(\mathrm{g})^{\star}$ & $3001 \pm 740$ \\
\hline Apgar score at 5 min, median (range) & $8(7,9)$ \\
\hline Mode of delivery (vaginal) & $16(64)$ \\
\hline Male sex & $14(56)$ \\
\hline Antenatal diagnosis & $23(92)$ \\
\hline Access & $16(64)$ \\
\hline Umbilical & $9(36)$ \\
\hline Femoral & $20(80)$ \\
\hline Preprocedure prostaglandin & $20(10,20)$ \\
\hline Maximum prostaglandin dose $(\mathrm{ng} / \mathrm{kg} / \mathrm{min})^{\star}$ & $3(2,4)$ \\
\hline Age at balloon atrial septostomy $(\mathrm{h})^{*}$ & \\
\hline
\end{tabular}

*Data were presented as mean \pm SD and median (IQR). $\mathrm{IQR}$, interquartile range; SD, standard deviation.

post-BAS oxygenation variables. Table 3 depicts lack of correlations between "change" in ASD size and "change" in oxygenation variables. One infant (32 weeks gestation, birth weight $1342 \mathrm{~g}$ ) died at 28 days of age due to necrotizing enterocolitis.

\section{DISCUSSION}

In our study on D-TGA infants with IVS, BAS led to significant improvement in oxygenation; however, ASD size and oxygenation variables showed no correlation. While the degree of "mixing" is one of the chief determinants of systemic arterial saturation levels and $\mathrm{paO}_{2}$, other factors, such as pulmonary hemodynamics, also may play important roles. Our study differs from previous ones because it includes a homogenous population of D-TGA infants with IVS. A VSD allows mixing between the two circulations, making the cohort quite dissimilar to those

Table 2 Comparison of pre-BAS and post-BAS oxygenation parameters $(n=25)$

\begin{tabular}{lllc}
\hline Variable & Pre-BAS & Post-BAS & P value \\
\hline $\mathrm{FiO}_{2}$ & $0.44 \pm 0.3$ & $0.36 \pm 0.27$ & 0.34 \\
$\mathrm{PaO}_{2}(\mathrm{mmHg})$ & $24 \pm 5$ & $40 \pm 6$ & $<0.001$ \\
$\mathrm{PaO}_{2} / \mathrm{FiO}_{2}$ & $83 \pm 44$ & $155 \pm 64$ & $<0.001$ \\
$\begin{array}{l}\mathrm{Oxygen} \text { saturations/ } \\
\mathrm{FiO}_{2}\end{array}$ & $232 \pm 135$ & $314 \pm 130$ & 0.037 \\
$\begin{array}{l}\text { Preductal oxygen } \\
\text { saturations (\%) }\end{array}$ & $67 \pm 18$ & $81 \pm 11$ & 0.003 \\
\hline $\begin{array}{l}\text { Oxygenation index } \\
\text { Oriong }\end{array}$ & $8.8(6,22)$ & $4.4(3.3,7.3)$ & 0.03
\end{tabular}

Oxygenation index $=\left(\mathrm{MAP} \times \mathrm{FiO}_{2}\right) / \mathrm{paO}_{2}$.

*Data were presented as median (IQR).

BAS, balloon atrial septostomy; $\mathrm{FiO}_{2}$, fractional inspired oxygen; $\mathrm{IQR}$, interquartile range; MAP, mean airway pressure; $\mathrm{paO}_{2}$, partial pressure of oxygen. 
Table 3 Correlations between change in atrial septal defect size and change in oxygenation variables $(n=25)$

\begin{tabular}{lll}
\hline Variable & R & P value \\
\hline $\mathrm{FiO}_{2}$ & -0.01 & 0.96 \\
$\mathrm{PaO}_{2}$ & -0.08 & 0.68 \\
$\mathrm{PaO}_{2} / \mathrm{FiO}_{2}$ & -0.19 & 0.35 \\
$\mathrm{Oxygen}$ & -0.08 & 0.7 \\
Preducturations $/ F \mathrm{FiO}_{2}$ & 0.22 & 0.28 \\
Oxygenation index & 0.23 & 0.26
\end{tabular}

Oxygenation index $=\left(\mathrm{MAP} \times \mathrm{FiO}_{2}\right) / \mathrm{paO}_{2}$.

$\mathrm{FiO}_{2}$, fractional inspired oxygen; MAP, mean airway pressure; $\mathrm{paO}_{2}$, partial pressure of oxygen.

with IVS. In much of the previous literature, 30\%-40\% of infants had a VSD. We performed BAS very early (median age of 3 hours) compared with previous studies; it is likely that pulmonary vascular resistance (PVR) is still quite high at this early age. Previous studies noted a wide range and a much later postnatal age at interventions. Prolonged suboptimal saturations themselves can lead to an elevated pulmonary artery resistance; this is an important factor affecting oxygenation. Clinical relevance of the findings is that while creating an adequate shunt is important when interatrial shunting is restrictive or when the saturations are low $(<75 \%$ in this study), beyond a certain size, there might be other hemodynamic variables, which may influence oxygenation. Lack of correlation between ASD size and oxygen saturations precludes us suggesting a cut-off for size that might correlate with $>75 \%$ saturations.

In a study on 45 infants where BAS was performed at $<6$ months of age, $18(40 \%)$ infants had a VSD,. ${ }^{3}$ This study defined satisfactory BAS as a $10 \%$ increase in saturations; $20 \%$ infants did not achieve this. In a study of 43 infants (more than half were $>7$ days old), BAS increased saturations by $>10 \%$ in 19/43 (44\%) infants,. ${ }^{4}$ Post-BAS ASD size did not correlate with post-BAS saturations. Sixteen infants $(37 \%)$ in this cohort had a large VSD. More recently, Cherif et al studied 13 infants with TGA who underwent BAS at a median age of 20 days (range 2-60 days). ${ }^{2}$ No correlation between the ASD diameter and the increase of systemic saturation after BAS was noted. In a single-center retrospective review where 20 (33\%) infants had a VSD, while saturations increased significantly, no correlations with shunt size was noted. BAS was performed at a much later age compared with our cohort [median 15.5 hours (1.5 to 168 hours).$^{5}$

Evidently, the available literature is quite heterogeneous in terms of the presence or absence of VSDs, whether septostomy was done, whether prostaglandins were used and the postnatal age at which septostomy was performed. Baylen $e t$ alnoted that among 23 infants, 15 infants (group 1) did not undergo septostomy, and 8 (group 2) underwent septostomy. Before prostaglandin infusion, mean $\mathrm{paO}_{2}$ in group $1(26 \mathrm{mmHg}$ ) was comparable to group 2 (25 mmHg). In group $1, \mathrm{paO}_{2}$ increased to $43 \pm 8 \mathrm{mmHg}$ after prostaglandin infusion, but no increase was noted in group 2. The $\mathrm{paO}_{2}$ increased to $43 \pm 4 \mathrm{mmHg}$ (comparable to that in group 1 ) only after septostomy. This indicated the moderating role of prostaglandins in influencing pulmonary circulation. This study noted that in group 2 (septostomy group $=8$ infants), BAS was done at the range of $6-269$ hours $(<48$ hours for all infants except one); ASD diameter influenced arterial oxygenation during prostaglandin infusion. ${ }^{1}$ The ASD dimensions were measured using 2D imaging,. ${ }^{1}$ While most recent assessments of ASD size use echocardiography, in a preprostaglandin era study, the ASD diameter was determined by measuring the diameter of a balloon that could be pulled from left atrium to right atrium without deformity. ${ }^{4}$ More recently, Hiremath et al administered in prostaglandins in 58/60 (96\%) infants and noted that the post-BAS ASD size did not correlate with post-BAS saturations. However, $20(33 \%)$ infants in this cohort had a VSD. ASD size was measured by echocardiography although the mode "2-D" was not specified. In retrospective data on 30 infants, of whom $6(20 \%)$ had a VSD, postprocedure oxygen saturation $>60 \%$ with at least $>10 \%$ improvement from preprocedure levels were defined as an optimal result. There was no difference in demographic variables or in ASD size before and after BAS among those who did or did not achieve the optimal result. Prostaglandins were not used in this study. The ASD size was measured by echocardiography although the mode was not specified,. ${ }^{6}$

With optimized interatrial mixing, the pulmonary-tosystemic blood flow ratio may be the primary determinant of arterial oxygen saturation. Reduction in pulmonary blood flow by subpulmonary, pulmonary stenosis or elevated PVR may lower the oxygen saturations despite adequately sized anatomic shunting sites. Delayed BAS and prolonged suboptimal saturations pre-BAS may contribute to an elevated PVR. PGE1 infusion may partly alleviate this; rapid discontinuation of PGE1 after BAS was associated with an increased risk of rebound hypoxemia. A recent study showed that early cessation of PGE1, less than 2 hours after septostomy, was associated with greater rebound hypoxemia than when PGE1 was stopped more than 2 hours following septostomy,. ${ }^{7}$ Prostaglandins maintain ductal patency (and hence improve mixing) and may mediate pulmonary vasodilation in response to ventilation at birth. Another possibility may be that the atrial gap may contract after septostomy, that is, the atrial septum is not actually torn but stretched. Systemic arterial blood in D-TGA is derived from two sources, and the systemic arterial oxygen saturation is dependent on their relative proportions. These include highly saturated pulmonary venous blood that has been shunted from the pulmonary to the systemic circuit (termed the "effective" systemic flow) and the blood reaching the aorta (low oxygen systemic mixed venous blood) that is being recirculated through the systemic circuit. BAS procedure does improve mixing and oxygenation, although poor mixing may still occur because of a persistently high PVR. A 
reassessment of oxygenation and echocardiographic data after a day or two may better reflect the true effects of BAS on circulatory mixing.

Advancement in echocardiography techniques and software allows easy assessment of ASD size postprocedure. This can preclude repeated procedures to further widen the defect. Early recognition of "poor mixing" because of high PVR can potentially rationalize care and facilitate earlier transfer for arterial switch. Retrospective study design and small numbers are among the study's limitations. In our study, BAS was performed very early on the first postnatal day when PVR is likely to be inherently high. We did not perform subsequent assessments during the next few days after BAS, which would have been useful. The indications of starting PGE1 and its subsequent dosage, while generally similar, varied according to patient profile and individual physician practices. Nonetheless, our data bring a renewed focus on the understanding of the circulatory physiology in infants with TGA undergoing BAS. Retaining focus on infants with TGA with IVS makes the study homogenous, avoiding the physiological constructs arising from an additional (ventricular) source of mixing of blood.

In conclusion, infants with TGA and IVS benefit from BAS in terms of improvement in oxygenation parameters. While BAS aims at increasing the ASD size and improving circulatory mixing, the ASD size did not correlate with immediate improvement in oxygenation.

Contributors SK contributed to conceptualization, data curation, formal analysis, investigation, methodology, writing —original draft. SK is responsible for conceptualization, data curation, formal analysis, investigation, methodology, writing —original draft. VS contributed to conceptualization, formal analysis, investigation, methodology, project administration, supervision, validation, writing一review and editing.
Funding The authors have not declared a specific grant for this research from any funding agency in the public, commercial or not-for-profit sectors.

Competing interests None declared.

Patient consent for publication Not required.

Ethics approval This retrospective study was conducted at Monash Children's Hospital, Melbourne, Australia after approval from the hospital ethics committee (RES-20-0000481Q - 66597).

Provenance and peer review Not commissioned; externally peer reviewed.

Data availability statement All data relevant to the study are included in the article or uploaded as supplementary information. All data relevant to the study are included in the article.

Open access This is an open access article distributed in accordance with the Creative Commons Attribution Non Commercial (CC BY-NC 4.0) license, which permits others to distribute, remix, adapt, build upon this work non-commercially, and license their derivative works on different terms, provided the original work is properly cited, appropriate credit is given, any changes made indicated, and the use is non-commercial. See: http://creativecommons.org/licenses/by-nc/4.0/.

ORCID iD

Kartik Sehgal http://orcid.org/0000-0002-1213-5127

\section{REFERENCES}

1 Baylen BG, Grzeszczak M, Gleason ME, et al. Role of balloon atrial septostomy before early arterial switch repair of transposition of the great arteries. J Am Coll Cardiol 1992;19:1025-31.

2 Cherif A, Mourali S, Farhati A, et al. [The immediate effect of Rashkind's atrioseptostomy on systemic saturation in transposition of the great arteries]. Tunis Med 2004:82:1107-10.

3 Neches WH, Park SC, Ettedgui JA. The science and practice of pediatric cardiology. 2nd edn. Baltimore: Williams and Wilkins, 1998: 1488-9.

4 Baker F, Baker L, Zoltun R, et al. Effectiveness of the Rashkind procedure in transposition of the great arteries in infants. Circulation 1971:43:1-6.

5 Hiremath G, Natarajan G, Math D, et al. Impact of balloon atrial septostomy in neonates with transposition of great arteries. $J$ Perinatol 2011;31:494-9.

6 Singhi AK, Vaidyanathan B, Francis E. Suboptimal results after balloon atrial septostomy in simple transposition. Abstract, annual conference of pediatric cardiology Society of India in 2007.

7 Finan E, Mak W, Bismilla Z, et al. Early discontinuation of intravenous prostaglandin E1 after balloon atrial septostomy is associated with an increased risk of rebound hypoxemia. J Perinatol 2008;28:341-6. 